\title{
Multisystem inflammatory syndrome in adults: a case report and review of the literature
}

\author{
Fardad Behzadi ${ }^{1}$, Nicolas A. Ulloa ${ }^{2^{*}}$ and Mauricio Danckers ${ }^{3}$
}

\begin{abstract}
Background: The current coronavirus disease pandemic has brought recognition of multisystem inflammatory syndrome in adults as a de novo entity, temporally associated with severe acute respiratory syndrome coronavirus 2 viral infection in adults. Hypothesis about its true pathophysiology remains controversial.

Case report: The patient was a 22-year-old African American female presenting to the emergency department with fever, sore throat, and neck swelling for the past 3 days. During her initial emergency department visit, her blood pressure was stable at $110 / 57 \mathrm{mmHg}$, temperature of $39.4^{\circ} \mathrm{C}$, and heart rate of 150 beats per minute. While in the emergency department, she received broad-spectrum antibiotics (vancomycin and ceftriaxone) and $30 \mathrm{cc} / \mathrm{kg}$ bolus of normal saline. Originally, she was admitted to a telemetry floor. The following night, a rapid response code was called due to hypotension. At that time, her blood pressure was $80 / 57 \mathrm{mmHg}$. She appeared comfortable without signs of respiratory distress. She received intravenous fluids and vasopressors, and was transferred to the intensive care unit. The patient had reported a previous coronavirus disease infection a few weeks prior. She was diagnosed and treated for multisystem inflammatory syndrome in adults. Intravenous immunoglobulin infusion was initiated and completed on hospital day 5. She was weaned off vasopressors by day 6, and discharged home on day 11 .

Conclusion: Our case report is an example of the presentation, diagnosis, and management of multisystem inflammatory syndrome. Our research into previous case reports illustrates the wide range of presentations, degree of end organ damage, and treatment modalities. This diagnosis needs to be considered in the presence of recent coronavirus disease infection with new-onset end organ failure, as prompt diagnosis and treatment is crucial for better outcomes.
\end{abstract}

Keywords: COVID, MIS-A, Organ failure, Pandemic, Case report

\section{Background}

The current coronavirus disease (COVID-19) pandemic has brought the recognition of multisystem inflammatory syndrome in adults (MIS-A) as a de novo entity temporally associated with severe acute respiratory syndrome coronavirus 2 (SARS-CoV-2) viral infection in adults. Hypothesis about its true pathophysiology remains

*Correspondence: nicolasulloa@hcahealthcare.com

2 Department of Emergency Medicine, Aventura Hospital and Medical Center, Miami, FL, USA

Full list of author information is available at the end of the article controversial. Its initial presentation, response to empiric therapy, and clinical outcomes are widely variable. We report the case of a 22-year-old female who presented with distributive shock after 3 days of fever, sore throat, and right-sided neck pain. She was diagnosed with MIS-A and successfully treated. We further provided the reader with an in-depth review of the current published case report of MIS-A available in the medical literature, and review the pathophysiology and clinical resemblance and difference to Kawasaki disease. original author(s) and the source, provide a link to the Creative Commons licence, and indicate if changes were made. The images or other third party material in this article are included in the article's Creative Commons licence, unless indicated otherwise in a credit line to the material. If material is not included in the article's Creative Commons licence and your intended use is not permitted by statutory regulation or exceeds the permitted use, you will need to obtain permission directly from the copyright holder. To view a copy of this licence, visit http://creativecommons.org/licenses/by/4.0/. The Creative Commons Public Domain Dedication waiver (http://creativeco mmons.org/publicdomain/zero/1.0/) applies to the data made available in this article, unless otherwise stated in a credit line to the data. 


\section{Case description}

A 22-year-old overweight African American female, with a body mass index (BMI) of $29.1 \mathrm{~kg} / \mathrm{m}^{2}$, presented to the emergency department (ED) with 3 days of fever, sore throat, right-sided neck pain, and swelling. She denied any respiratory symptoms. She had tested positive for SARS-CoV-2 by polymerase chain reaction (PCR) 4 weeks prior, complaining of fever, chills, cough, headache, and diarrhea for 1 week. At that time, she had visited the ED and had been discharged with acetaminophen. Per the patient, she was not discharged with steroids or antibiotics.

During her initial ED visit, her blood pressure was stable at $110 / 57 \mathrm{mmHg}$, temperature of $39.4{ }^{\circ} \mathrm{C}$, and heart rate of 150 beats per minute (BPM). While in the ED, she received broad spectrum antibiotics (vancomycin and ceftriaxone), $30 \mathrm{cc} / \mathrm{kg}$ bolus of normal saline, and blood cultures were obtained. Computed tomography (CT) of the neck with intravenous contrast revealed bilateral reactive lymphadenopathy with enlarged adenoids and mildly enlarged tonsillar pillars without abscesses. Initial chest X-ray was negative, without signs of pleural effusions or consolidations. Her electrocardiogram showed sinus tachycardia. She was admitted for persistent tachycardia and otolaryngology evaluation. Originally, the patient was admitted to a telemetry floor. The following night, a rapid response code was called due to hypotension. At that time, her blood pressure was $80 / 57 \mathrm{mmHg}$, heart rate was $125 \mathrm{BPM}$, respiratory rate of 25 , and temperature of $103 \mathrm{~F}$. She appeared comfortable, without signs of respiratory distress. She exhibited mild bilateral periorbital and lower extremities edema. Neck examination was notable for bilateral posterior lymphadenopathy with mild decreased range of motion. Her pulmonary and cardiac examinations were unremarkable other than tachycardia. Additionally, the rapid response team noted bilateral conjunctivitis as well as small strawberry rash diffusely. Another electrocardiogram was performed, which showed low voltage and sinus tachycardia. A point of care ultrasound (POCUS) was performed that was negative for pericardial effusion, right ventricular dilation, or signs of obstructive shock. She was fluid resuscitated with an additional $2 \mathrm{~L}$ of normal saline, with transient/negligible improvement of blood pressure. She was bolused another liter of lactated Ringer's, initiated norepinephrine infusion, and admitted to the intensive care unit (ICU) for the management of distributive shock.
Her follow-up studies showed a peak D-dimer of $3557 \mathrm{ng} / \mathrm{mL}, \mathrm{C}$-reactive protein (CRP) of $47 \mathrm{mg} / \mathrm{dL}$, and ferritin of $344 \mathrm{ng} / \mathrm{mL}$. Fibrinogen was $460 \mathrm{mg} / \mathrm{dL}$ and remained within normal limits. She has a nadir hemoglobin of $10.6 \mathrm{~g} / \mathrm{dL}, 24$-hour urinary protein of $560 \mathrm{mg}$ with preserved glomerular filtration rate through her entire hospital admission. Initial white blood cell count was 7000 cells $/ \mathrm{mm}^{3}$ and only increased slightly after corticosteroid use. She exhibited a mild elevation of aspartate transaminase (AST) to $46 \mathrm{U} / \mathrm{L}$, alanine transaminase (ALT) of $49 \mathrm{U} / \mathrm{L}$, and alkaline phosphate (ALP) of $51 \mathrm{U} / \mathrm{L}$. Her pro-B-type natriuretic peptide (BNP) was $3590 \mathrm{pg} /$ $\mathrm{mL}$ on hospital day 2 and her troponin I peaked at $0.257 \mathrm{ng} / \mathrm{m}$ on day 3 .

Official transthoracic echocardiography revealed a mild systolic dysfunction, grade 2 diastolic dysfunction and an ejection fraction of $40-45 \%$, and a concentric small pericardial effusion. Coronary angiography revealed normal coronaries without evidence of obstruction or aneurysms. CT angiogram of the chest was negative for pulmonary embolism but notable for moderate-sized pleural effusions bilaterally. Cardiac magnetic resonance imaging (MRI) was not performed.

The patient received supportive treatment with dynamic hemodynamic-driven preload resuscitation and vasopressor support with norepinephrine. Her maximum dose of norepinephrine was $5 \mathrm{mcg} /$ minute. Infectious disease was consulted on hospital day 3 , who broadened antibiotic coverage with $3.375 \mathrm{mg}$ piperacillin/tazobactam every 8 hours (q8) for 1 week. Broad infectious and immunologic workup was ordered and is summarized in Table 1. She tested negative for immunoglobulin (Ig) $\mathrm{M}$ and positive for IgG SARS-CoV-2 antibody. Dexamethasone $4 \mathrm{mg}$ was initiated in the ED and continued q12 hours until hospital day 5 when it was changed by infectious disease team to hydrocortisone $50 \mathrm{mg}$ q6 hours. Full-dose aspirin was initiated on hospital day 4 and continued until discharge. Intravenous immunoglobulin (IVIG) infusion was initiated and completed on hospital day 5 , when she received 80 g over 16 hours. She was weaned off vasopressors by hospital day 6 . An MRI of the neck without contrast on day 6 revealed resolution of her prevertebral soft tissue swelling and persistent nonspecific cervical lymphadenopathy bilaterally without any fluid collection. She received intravenous furosemide and albumin $25 \%$ intermittently with improvement in her interstitial edema. Blood and urine cultures remained negative during her hospitalization. She was discharged home on day 11 . 
Table 1 Infectious and immunologic panel

\begin{tabular}{|c|c|c|c|}
\hline Test & Result & Test & Result \\
\hline Hepatitis A IgM antibody & Negative & Human metapneumovirus (PCR) & Not detected \\
\hline Hepatitis B surface antigen & Negative & Syphilis serology & $<0.2 \mathrm{Al}$ \\
\hline Hepatitis B core IgM antibody & Negative & Adenovirus (PCR) & Not detected \\
\hline Hepatitis C antibody & Negative & Bordetella holmesii (PCR) & Not detected \\
\hline HSV I lgG antibody & $<0.2 \mathrm{Al}$ & Bordetella pertussis DNA (PCR) & Not detected \\
\hline HSV II IgG antibody & $<0.2 \mathrm{Al}$ & Bordetella pertussis /bronchoscopy PCR & Not detected \\
\hline HIV-1 and HIV-2 antigen and antibody & Nonreactive & Coxsackie type B (1) antibody & $1: 32 \mathrm{~A}$ \\
\hline Influenza A (RT-PCR) & Not detected & Coxsackie type B (2) antibody & $1: 16 \mathrm{~A}$ \\
\hline Influenza A H1 subtype (PCR) & Not detected & Coxsackie type B (3) antibody & $1: 16 \mathrm{~A}$ \\
\hline Influenza A H3 subtype (PCR) & Not detected & Coxsackie type B (4) antibody & $1: 16 \mathrm{~A}$ \\
\hline Influenza type B (PCR) & Not detected & Coxsackie type B (5) antibody & $1: 32 \mathrm{~A}$ \\
\hline Parainfluenza 2 (PCR) & Not detected & Coxsackie type B (6) antibody & $1: 32 \mathrm{~A}$ \\
\hline Parainfluenza 3 (PCR) & Not detected & CMV DNA (PCR) & Negative \\
\hline Parainfluenza 4 (PCR) & Not detected & RSV type A (PCR) & Not detected \\
\hline Group A strep screen & Negative & RSV type B (PCR) & Not detected \\
\hline Anti-streptolysin $\mathrm{O}$ antibody & $42 \mathrm{IU} / \mathrm{mL}$ & Rhinovirus (PCR) & Not detected \\
\hline SARS-CoV-2 IgG antibody & Positive & EBV DNA & Positive \\
\hline SARS-CoV-2 IgM antibody & Negative & Rheumatoid factor & Negative \\
\hline $\operatorname{lgG}$ total & 4247 mg/dL & ANA & Negative \\
\hline $\operatorname{lgG} 1$ & 1545 mg/dL & C-ANCA & $<0.2 \mathrm{Al}$ \\
\hline $\operatorname{lgG} 2$ & $639 \mathrm{mg} / \mathrm{dL}$ & P-ANCA & $<0.2 \mathrm{Al}$ \\
\hline $\lg G 3$ & $110 \mathrm{mg} / \mathrm{dL}$ & dsDNA antibody & $<1 \mathrm{IU} / \mathrm{mL}$ \\
\hline $\operatorname{lgG} 4$ & $44 \mathrm{mg} / \mathrm{dL}$ & Complement C3 & $70(\mathrm{~L}) \mathrm{mg} / \mathrm{dL}$ \\
\hline $\lg A$ & $63.6 \mathrm{mg} / \mathrm{dL}$ & Complement C4 & $<8(\mathrm{~L}) \mathrm{mg} / \mathrm{dL}$ \\
\hline
\end{tabular}

$R T-P C R$ reverse transcription-polymerase chain reaction, $H S V$ herpes simplex virus, HIV human immunodeficiency virus, $C M V$ cytomegalovirus, $R S V$ respiratory syncytial virus, EBV Epstein-Barr virus, dsDNA double strain DNA antibodies, ANA antinuclear antibody, C-ANCA antineutrophil cytoplasmic antibodies, $P-A N C A$ perinuclear antineutrophil cytoplasmic antibodies, IgM Immunoglobulin $M, \lg G \operatorname{Immunoglobulin} \mathrm{G}, \lg A \operatorname{Immunoglobulin} \mathrm{A}$

\section{Discussion}

Multisystem inflammatory syndrome in adults (MISA) was first mentioned in 2020 following the initial description of this syndrome in the pediatric population (multi-inflammatory syndrome in children) during the COVID-19 pandemic. Since its first recognition, several case reports have been published in the literature, with a wide range of clinical manifestations and therapeutic interventions. MIS-A is suspected to be caused by an abnormal immune response to SARS-CoV-2 infection and is commonly associated with clinical features such as fever, systemic inflammation, and shock with end-organ damage $[1,2]$. Many of these features have been proposed to resemble Kawasaki-like manifestations [1, 2]. According to the Centers of Disease Control (CDC), five criteria should be fulfilled to diagnosed MIS-A: (1) concurrent or previous (within the past 12 weeks) COVID19 diagnosed by either PCR or antigen/antibody testing, (2) severe sickness necessitating hospitalization in those aged 21 years or more, (3) marked involvement or dysfunction of single or multiple extrapulmonary organs (acute kidney injury, acute liver injury, neurological involvement, cardiac insult, shock, hypotension, and so on), (4) absence of severe respiratory affection (respiratory signs and symptoms), and (5) exhibiting severe inflammation as per laboratory findings: elevated CRP, D-dimer, serum ferritin, erythrocyte sedimentation rate (ESR), fibrinogen, interleukin-6 (IL-6) [3]. In our case, the patient fulfilled all five criteria to make the diagnosis.

Thirty-six documented cases of MIS-A were reviewed and are summarized in Table 2 . The mean age of patients was 33 years, with male predominance (23/36; 63\%). Most of the patients had no past medical history of significance (23/36; 63\%), while $17 / 36$ (47\%) contracted SARS-CoV-2 infection, suggested by PCR, antibody testing, or clinically. Fever was recorded in $31 / 36$ cases $(86 \%)$. Gastrointestinal symptoms were less frequently reported: nausea $(7 / 36,19 \%)$, abdominal pain $(11 / 36$; 30\%), vomiting $(5 / 36 ; 13 \%)$, and diarrhea $(7 / 36 ; 19 \%)$. Like our case report, sore throat was present in five patients $(5 / 36$; 14\%) [4-8] and unilateral cervical pain/swelling in four other cases $(6 / 36 ; 16 \%)$ [8-12]. Some patients had predominant visual symptoms [5, 13-17]. 


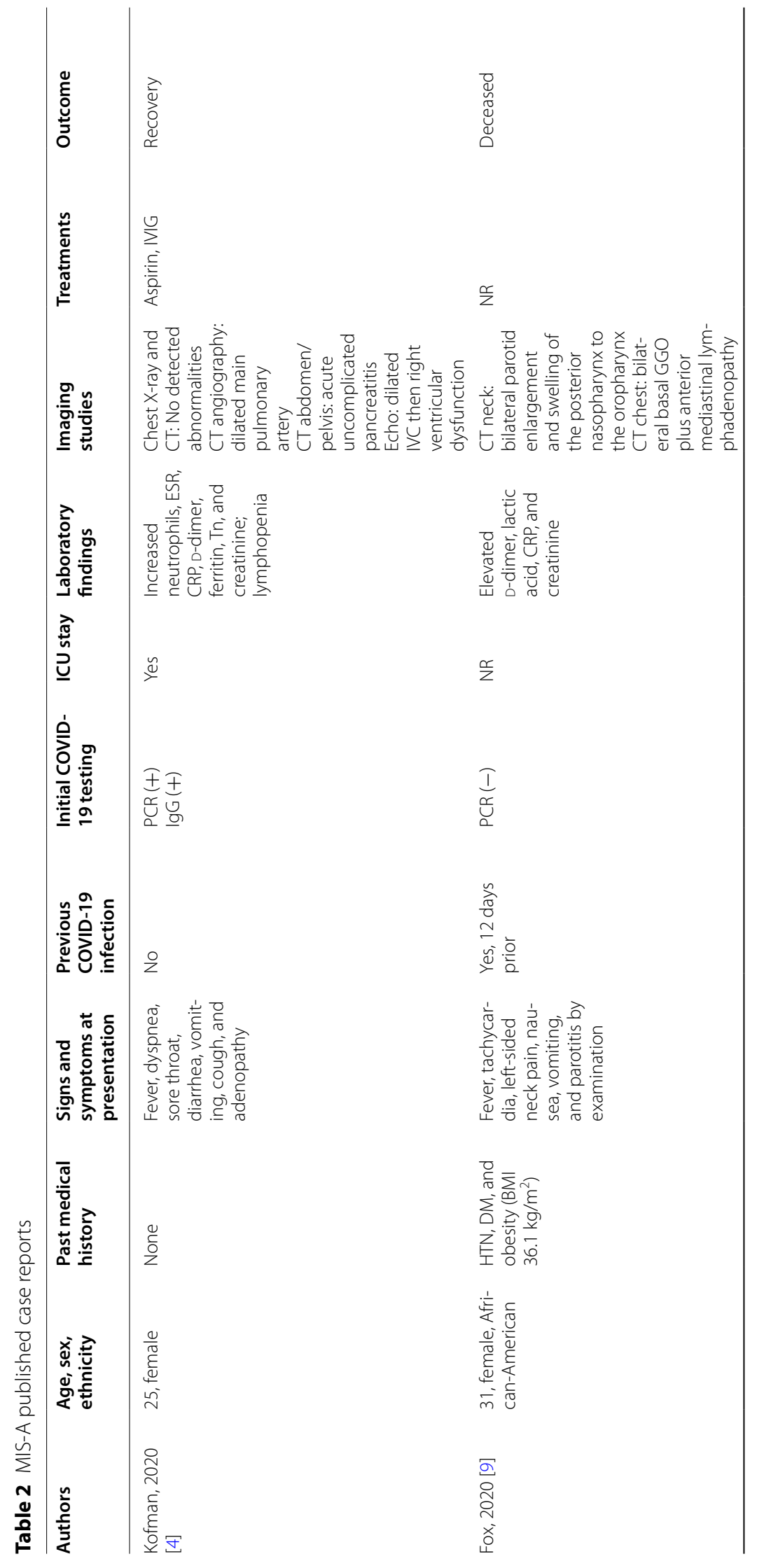




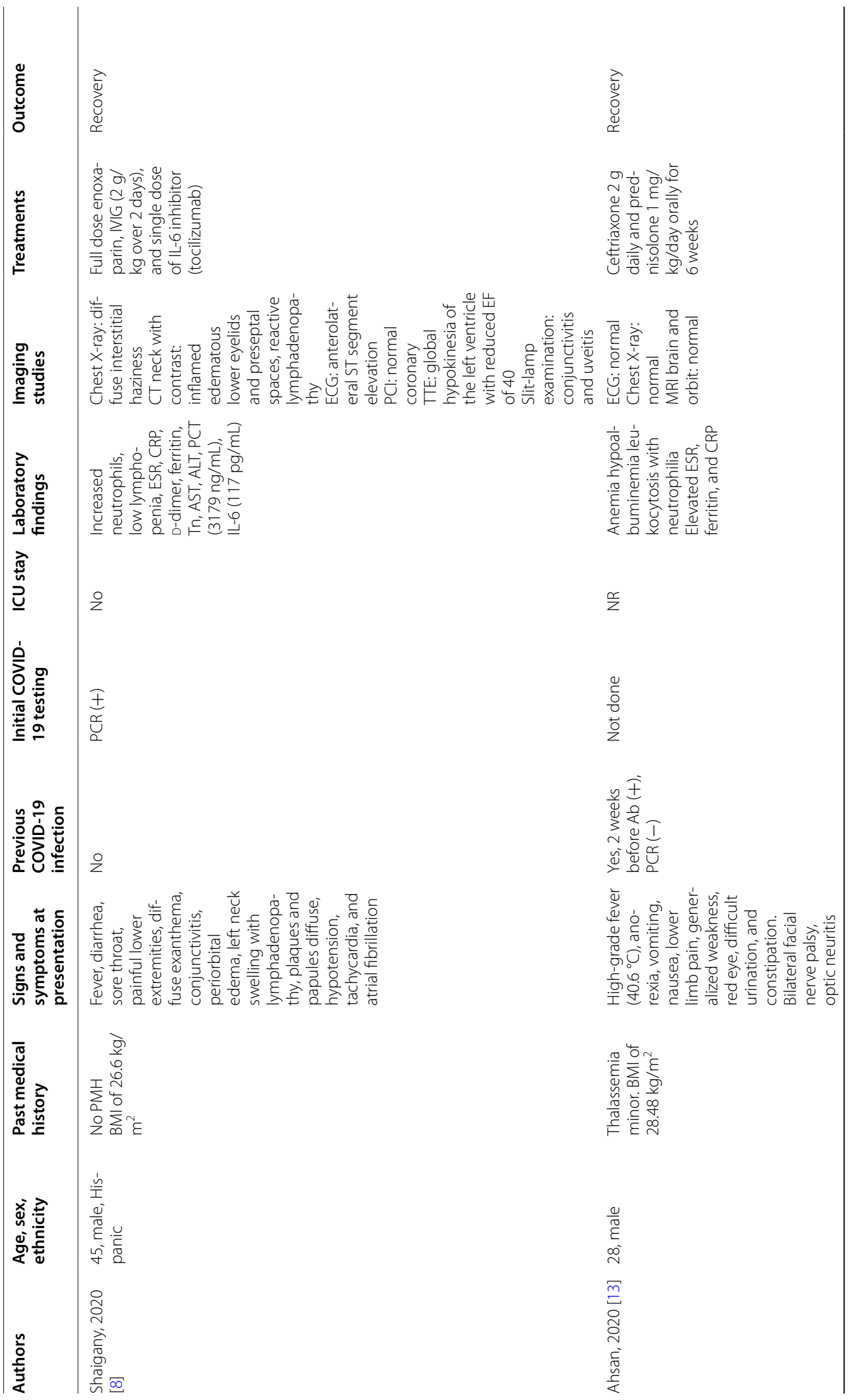




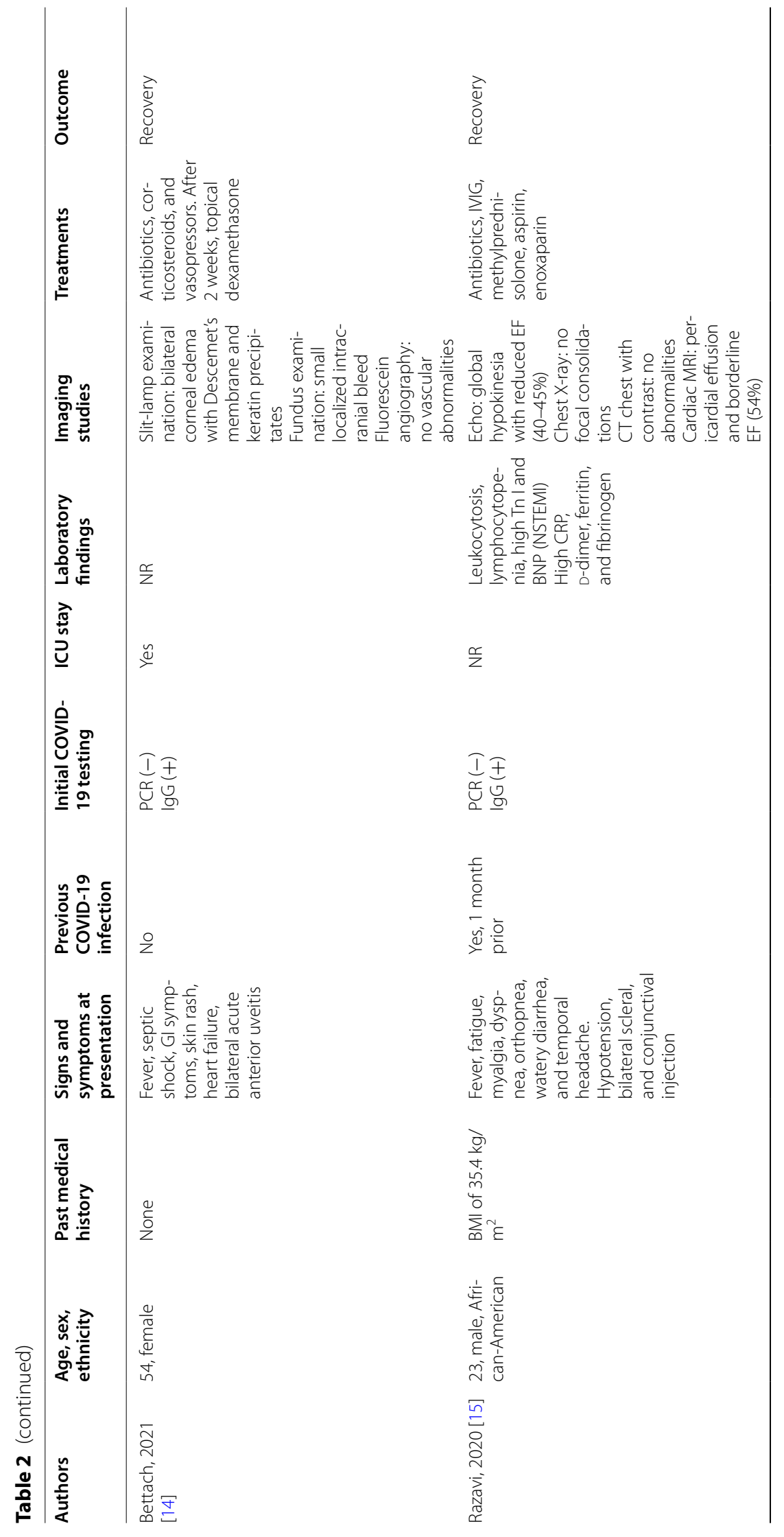




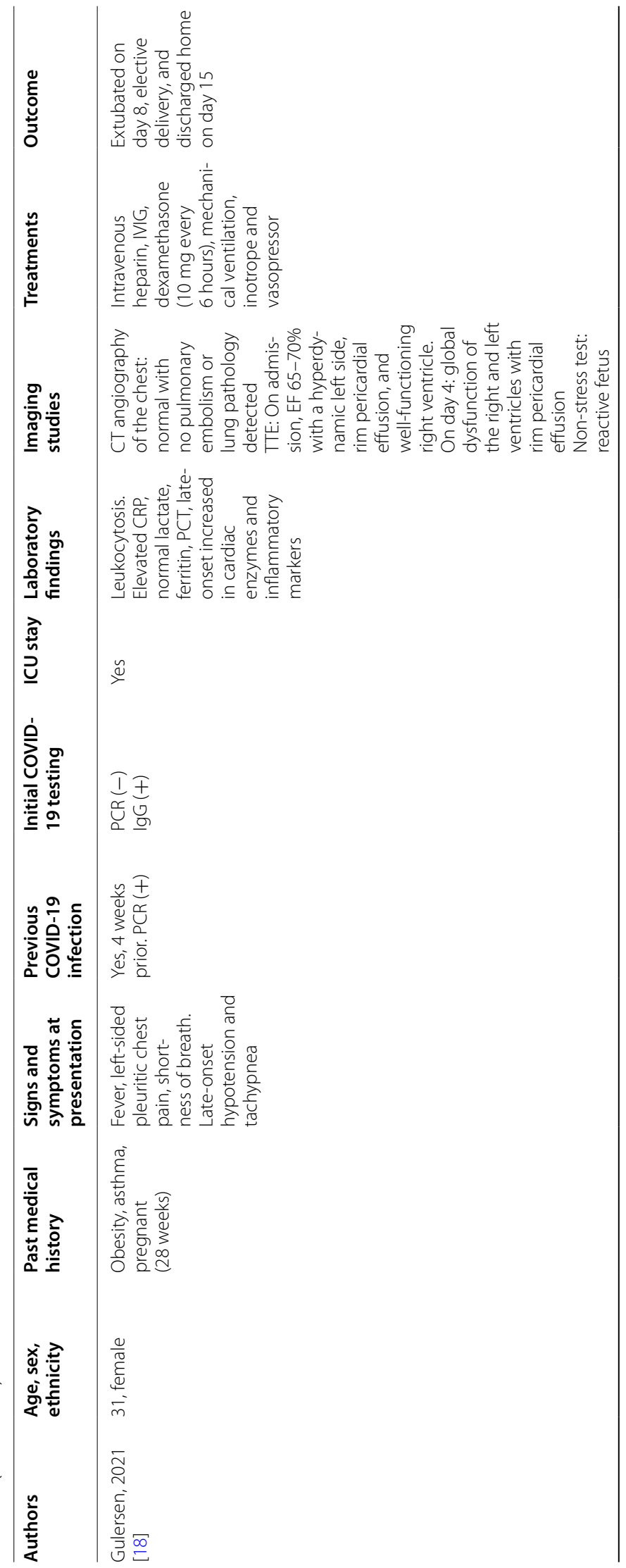




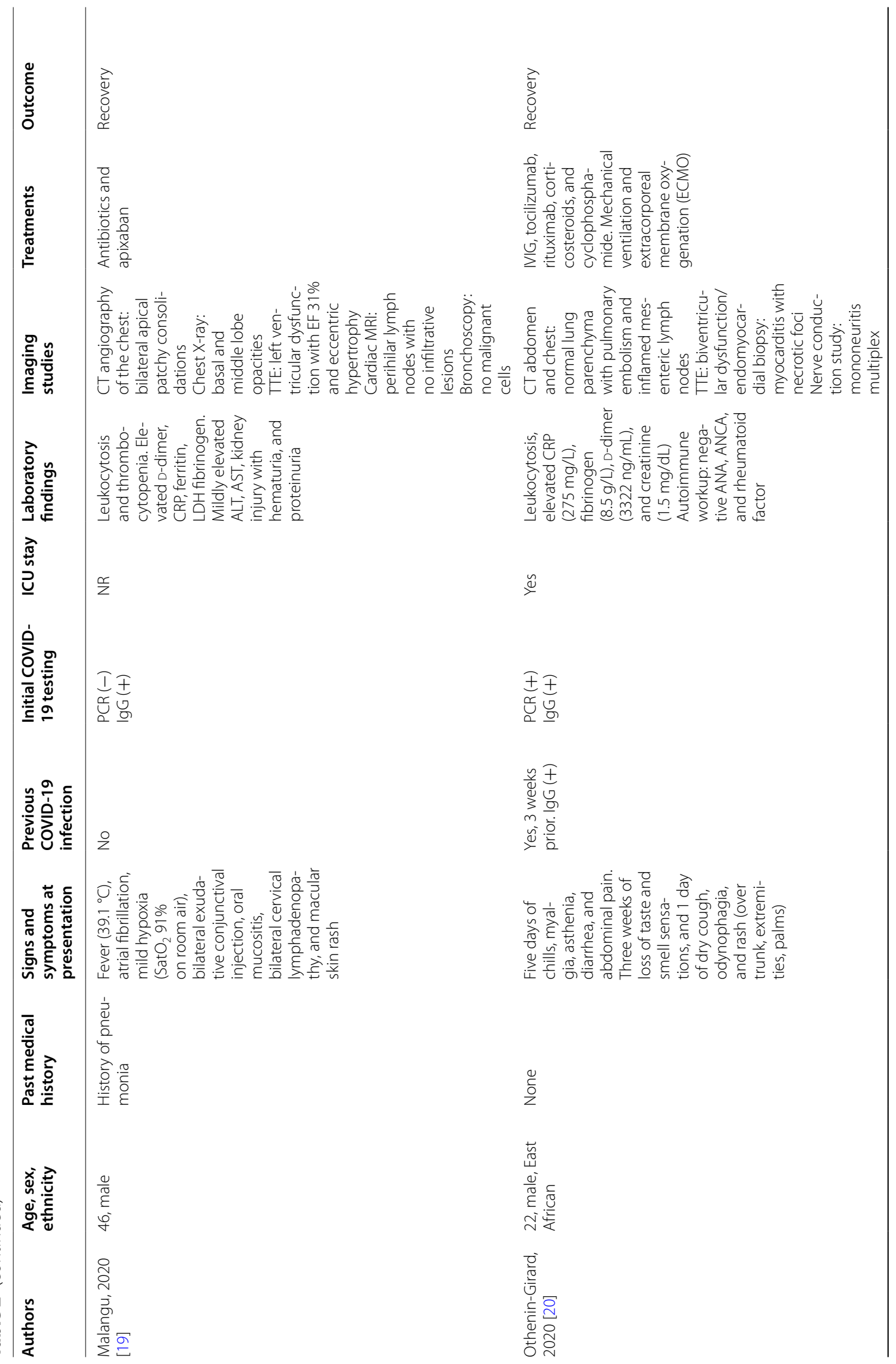




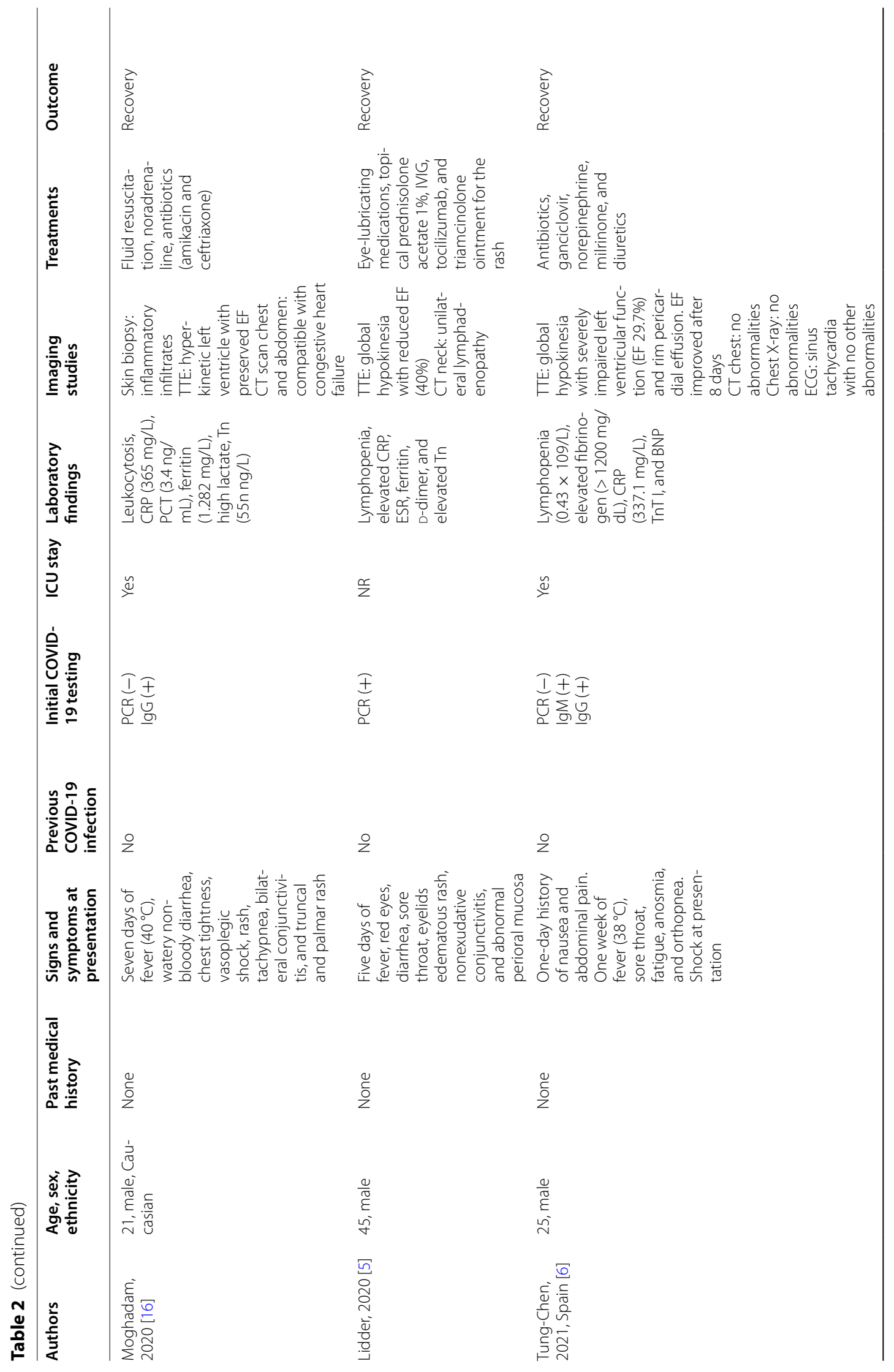




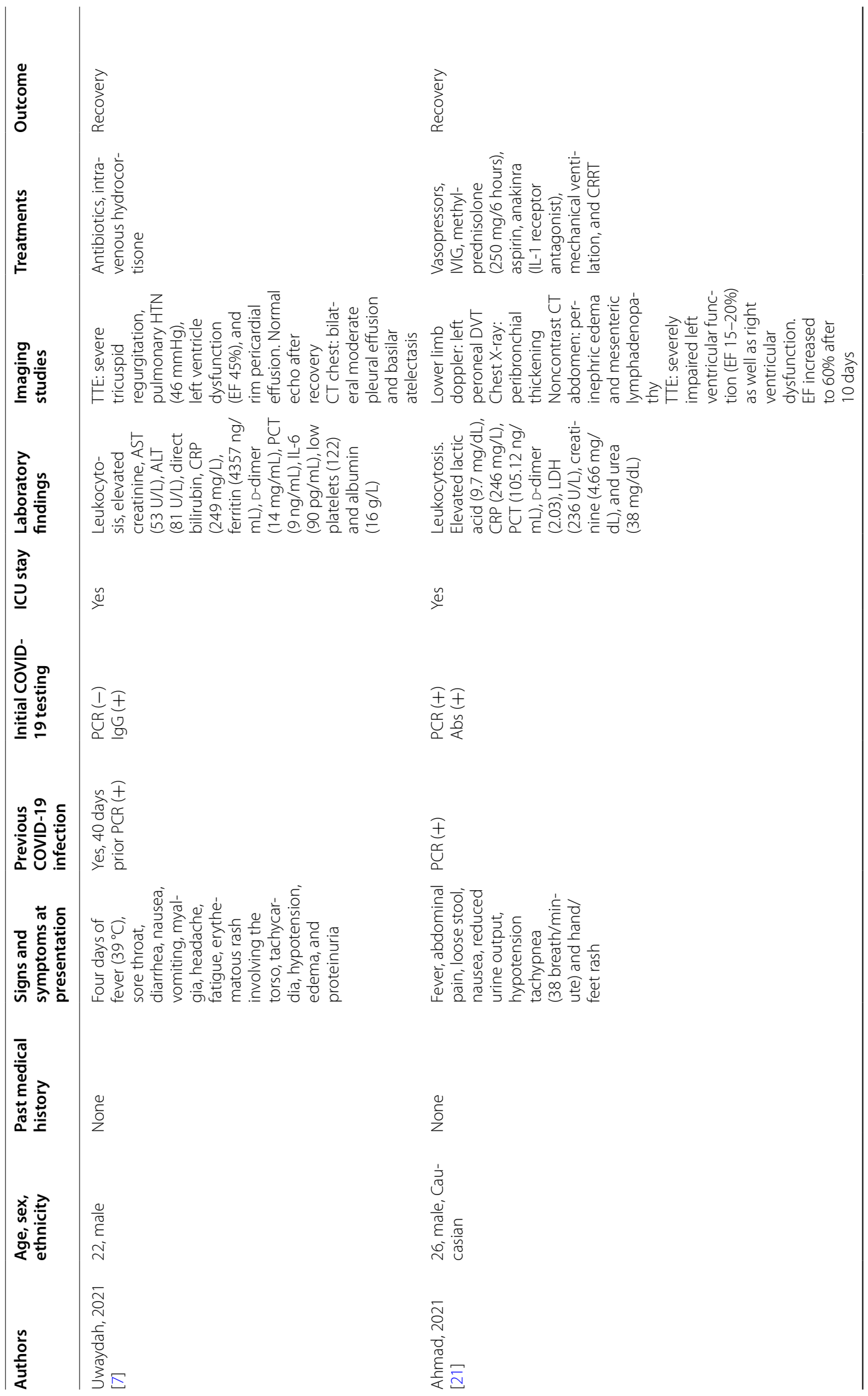




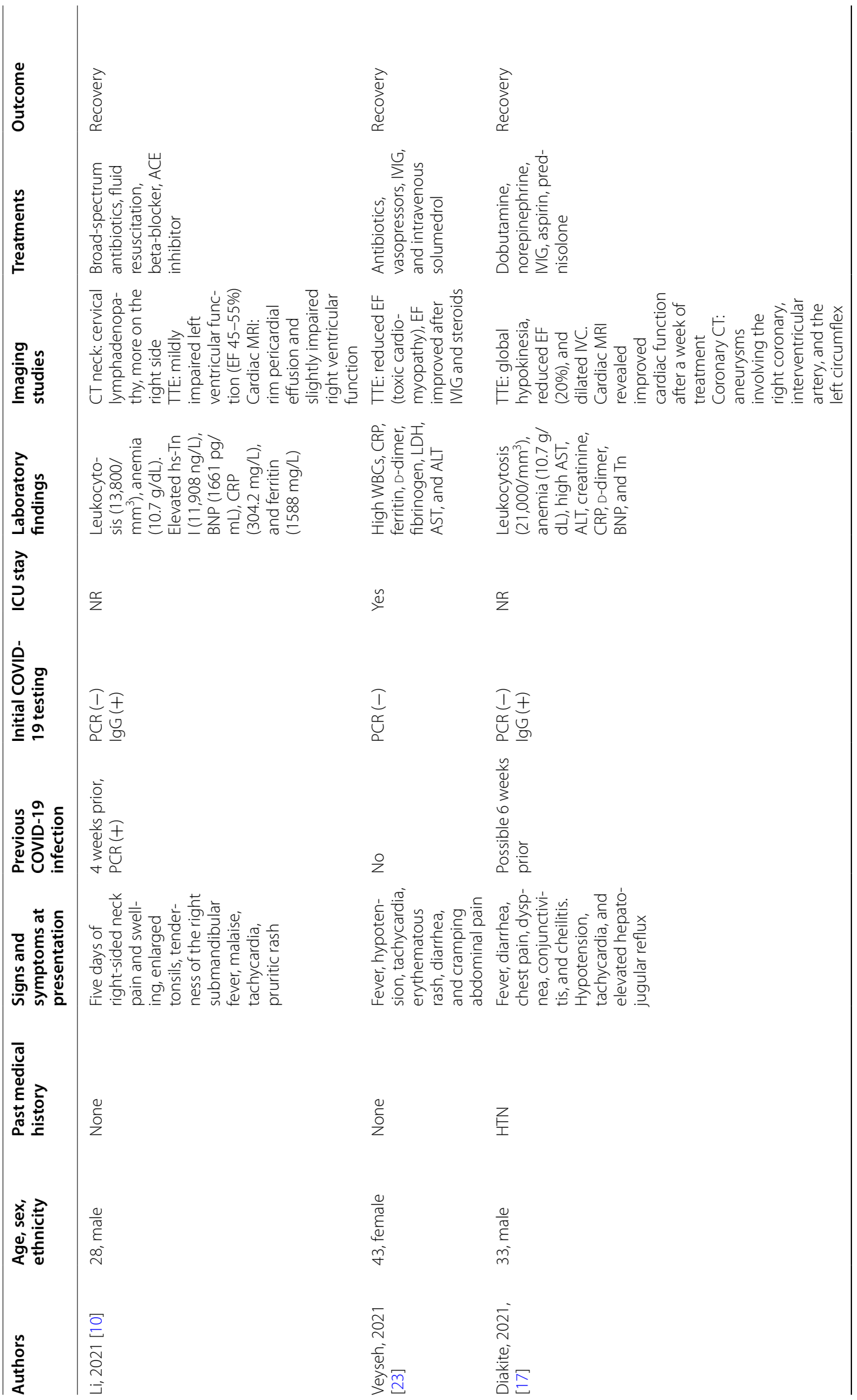




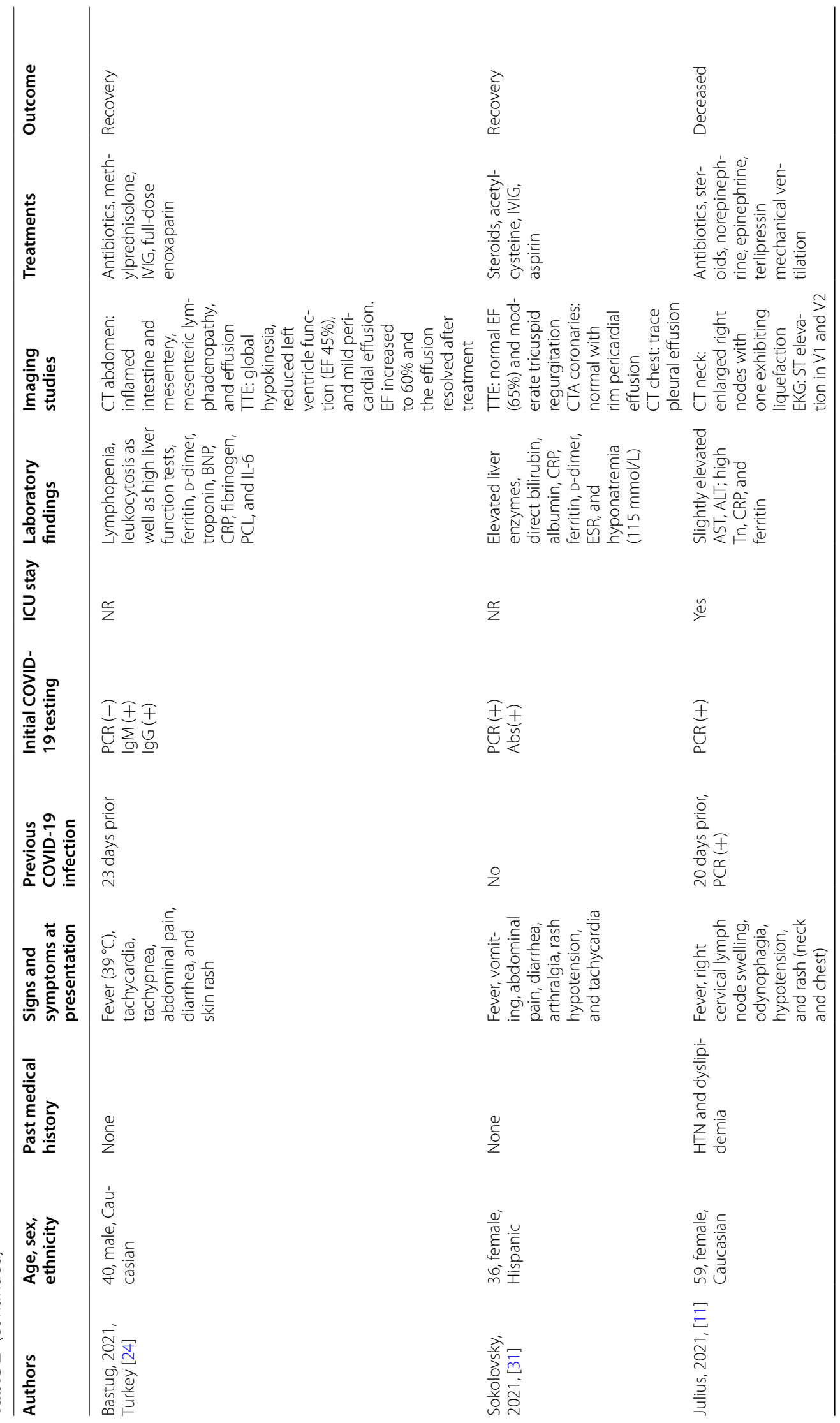




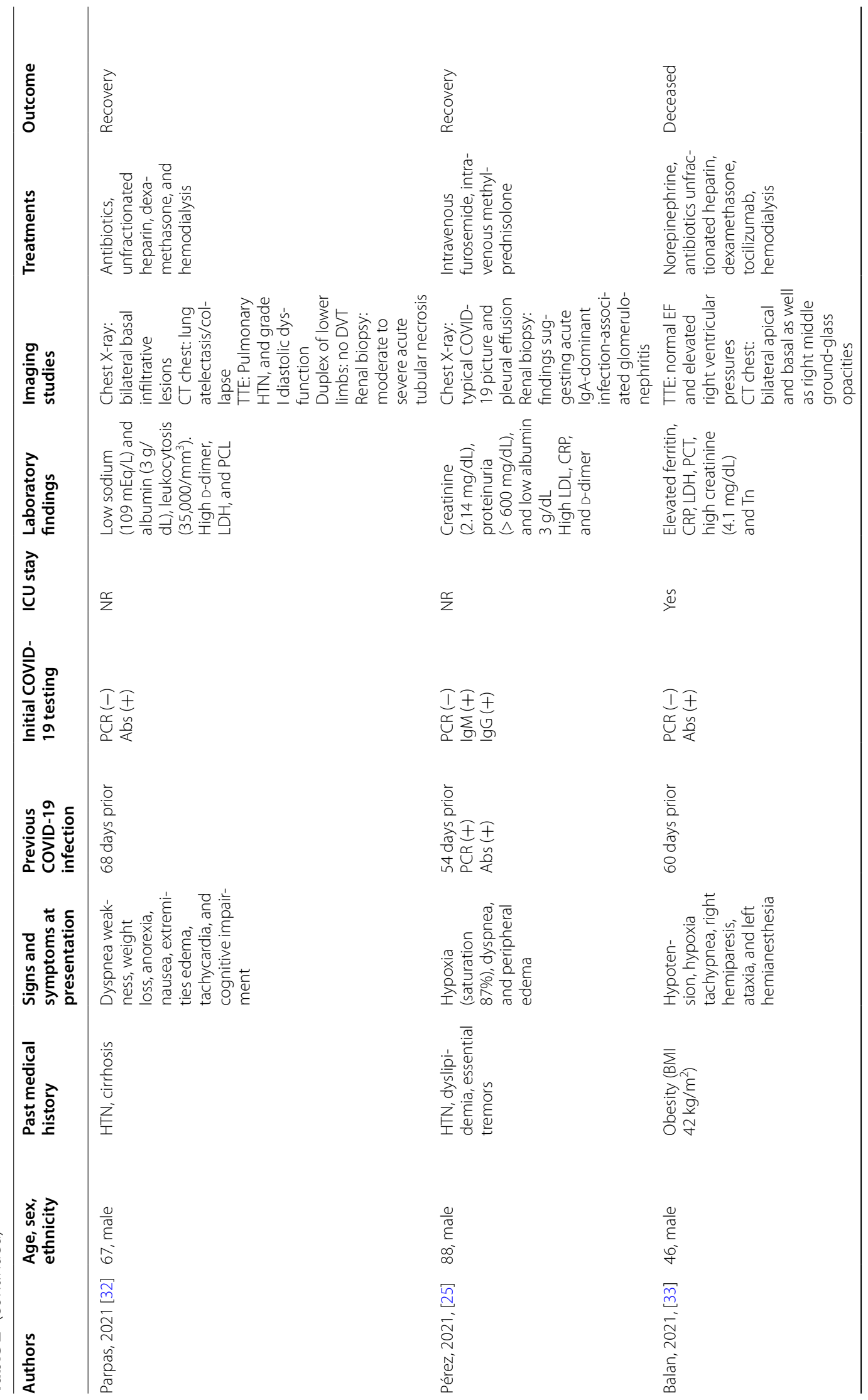




\begin{tabular}{|c|c|c|c|c|c|}
\hline 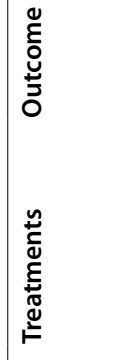 & 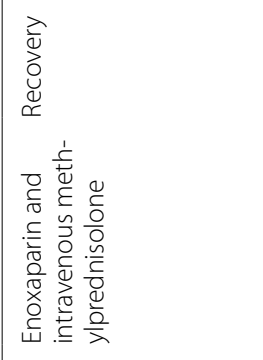 & 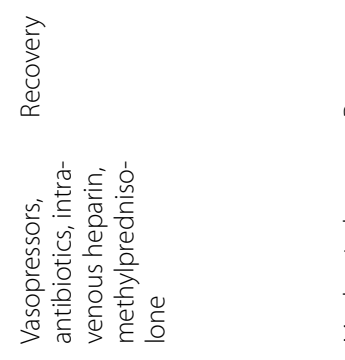 & 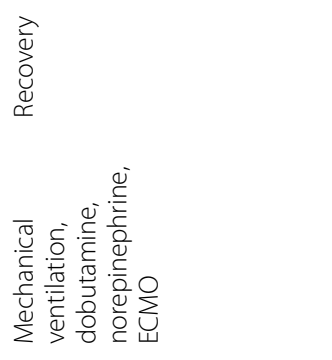 & 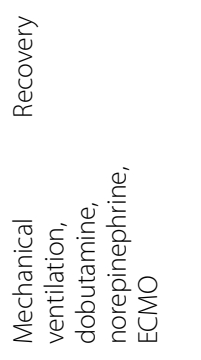 & 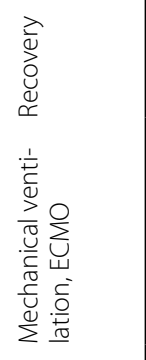 \\
\hline 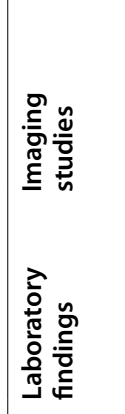 & 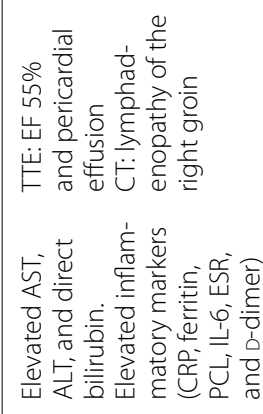 & 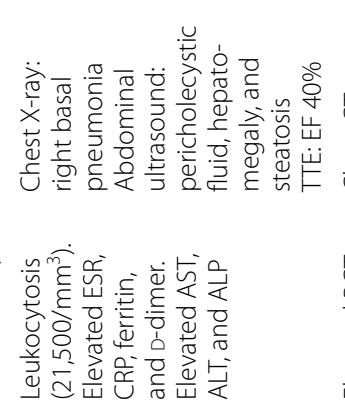 & 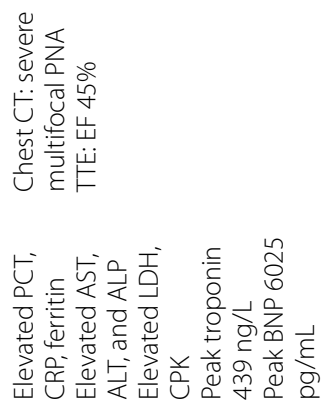 & 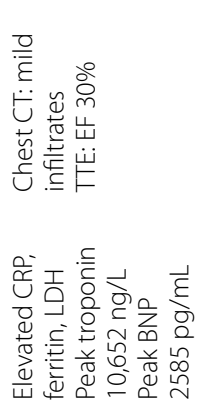 & 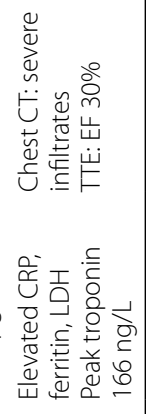 \\
\hline & $\frac{0}{2}$ & $\stackrel{\propto}{z}$ & $\stackrel{\breve{y}}{\searrow}$ & 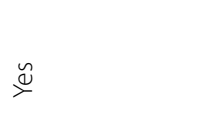 & $\stackrel{\oiiint}{\rightleftharpoons}$ \\
\hline 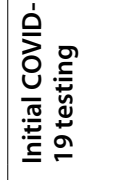 & 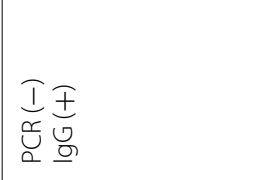 & 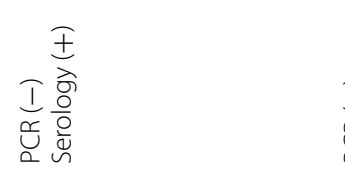 & 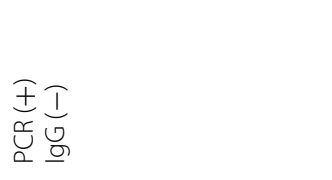 & 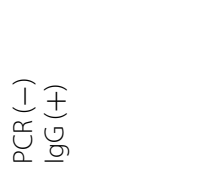 & 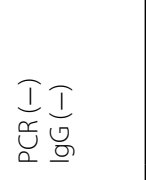 \\
\hline 气̆ & 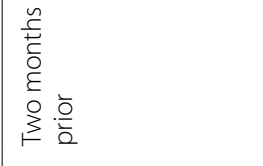 & $\stackrel{0}{z}$ & $\stackrel{0}{z}$ & $\stackrel{0}{z}$ & $\stackrel{o}{z}$ \\
\hline 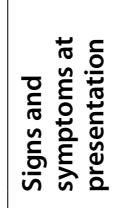 & 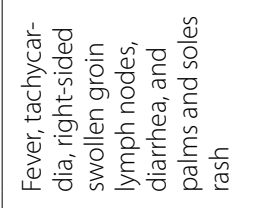 & 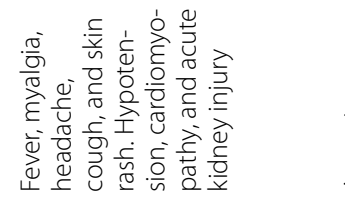 & 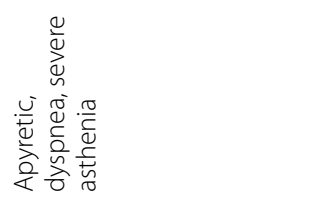 & 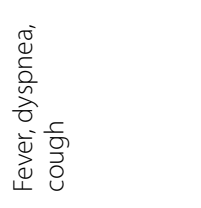 & 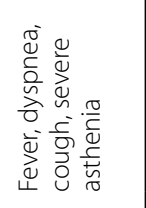 \\
\hline 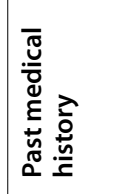 & 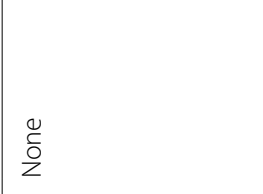 & $\begin{array}{l}\mathscr{\Sigma} \\
\frac{\tilde{\Sigma}}{2}\end{array}$ & 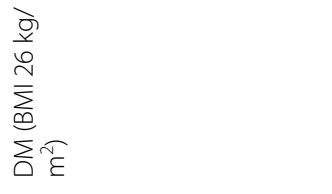 & 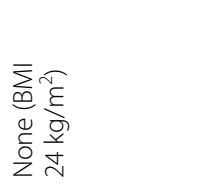 & 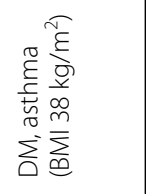 \\
\hline 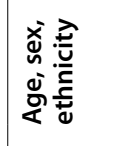 & \begin{tabular}{|l}
$\frac{0}{\tilde{\sigma}}$ \\
$\stackrel{\tilde{E}}{\tilde{N}}$ \\
$\tilde{m}$
\end{tabular} & 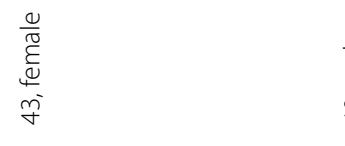 & $\begin{array}{l}\frac{0}{\tilde{\sigma}} \\
\frac{\sigma}{\sigma} \\
\end{array}$ & 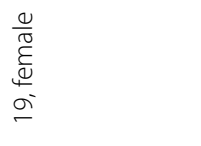 & 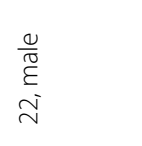 \\
\hline 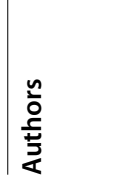 & 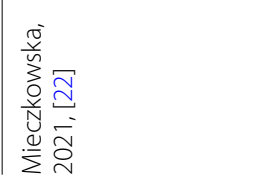 & 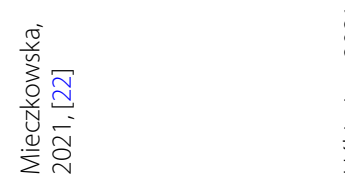 & 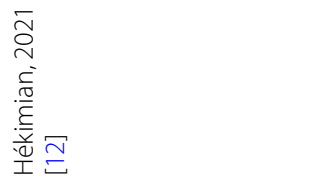 & 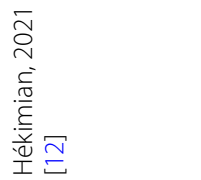 & 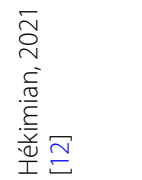 \\
\hline
\end{tabular}




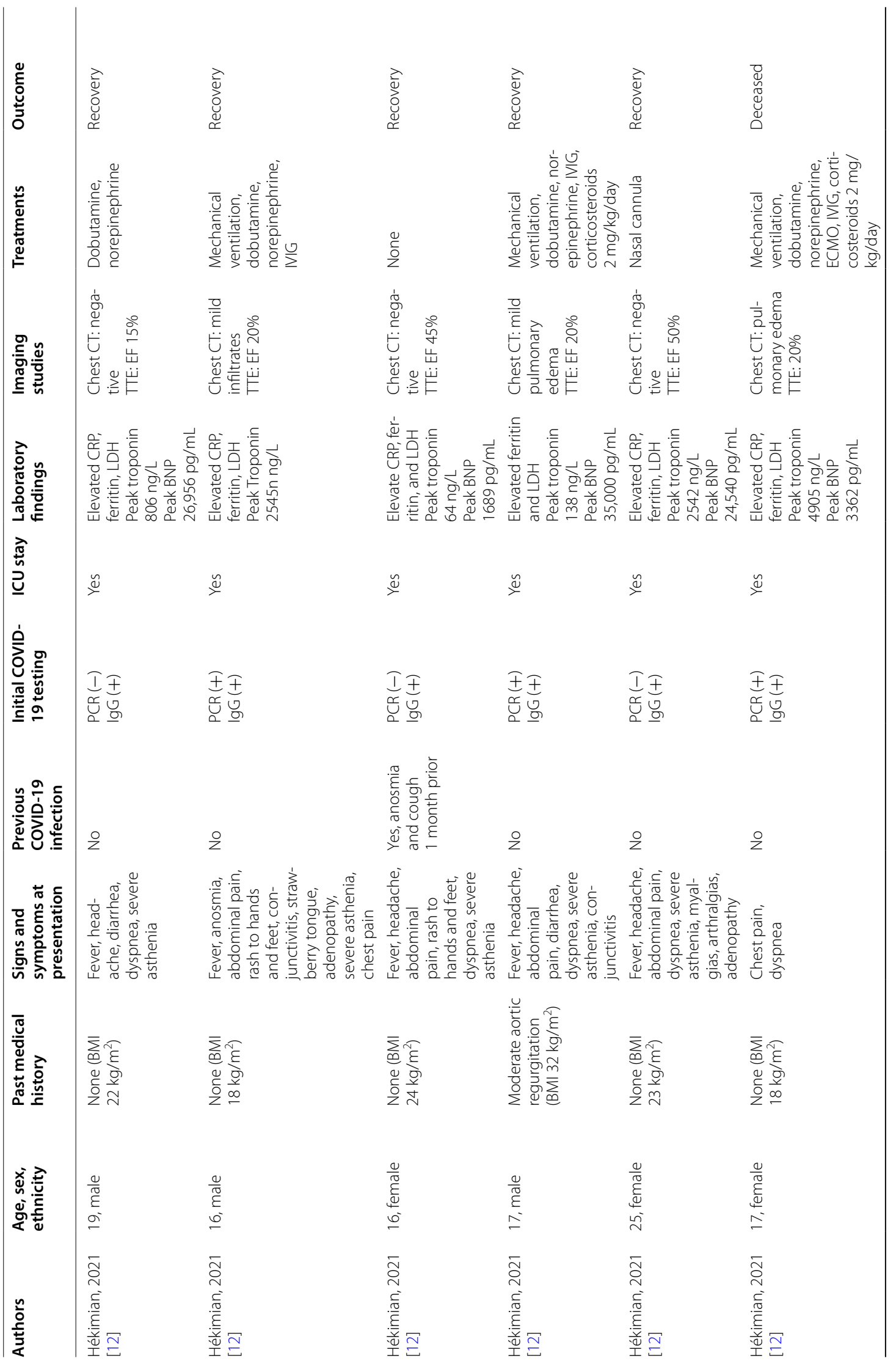




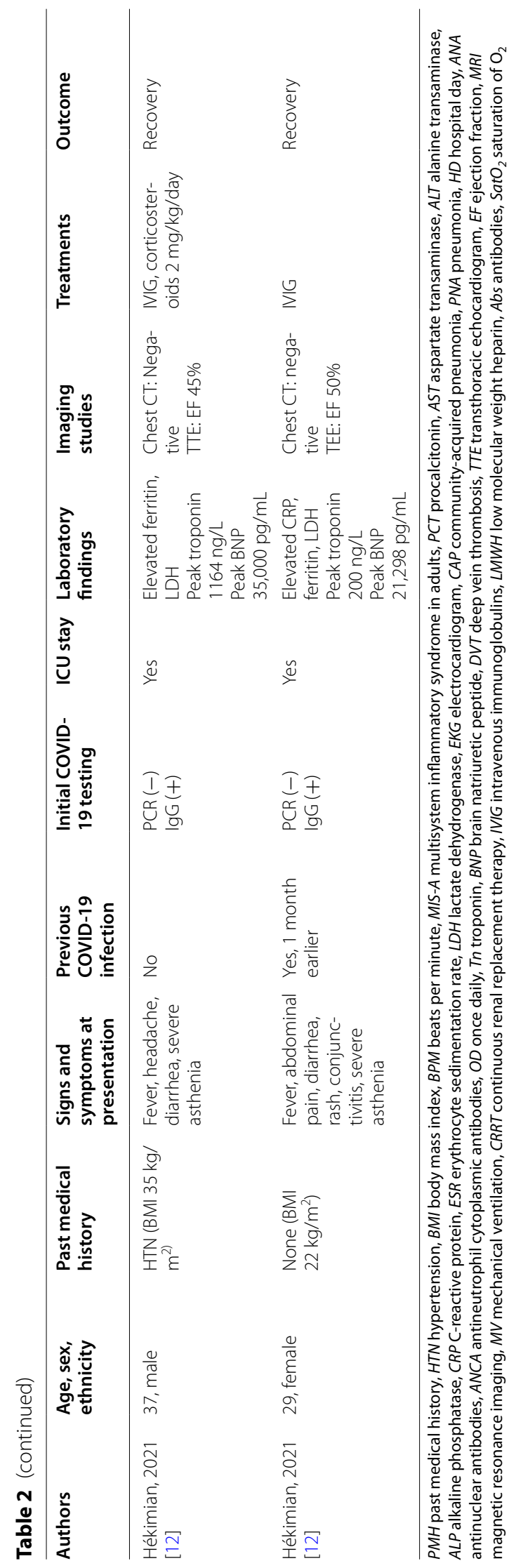




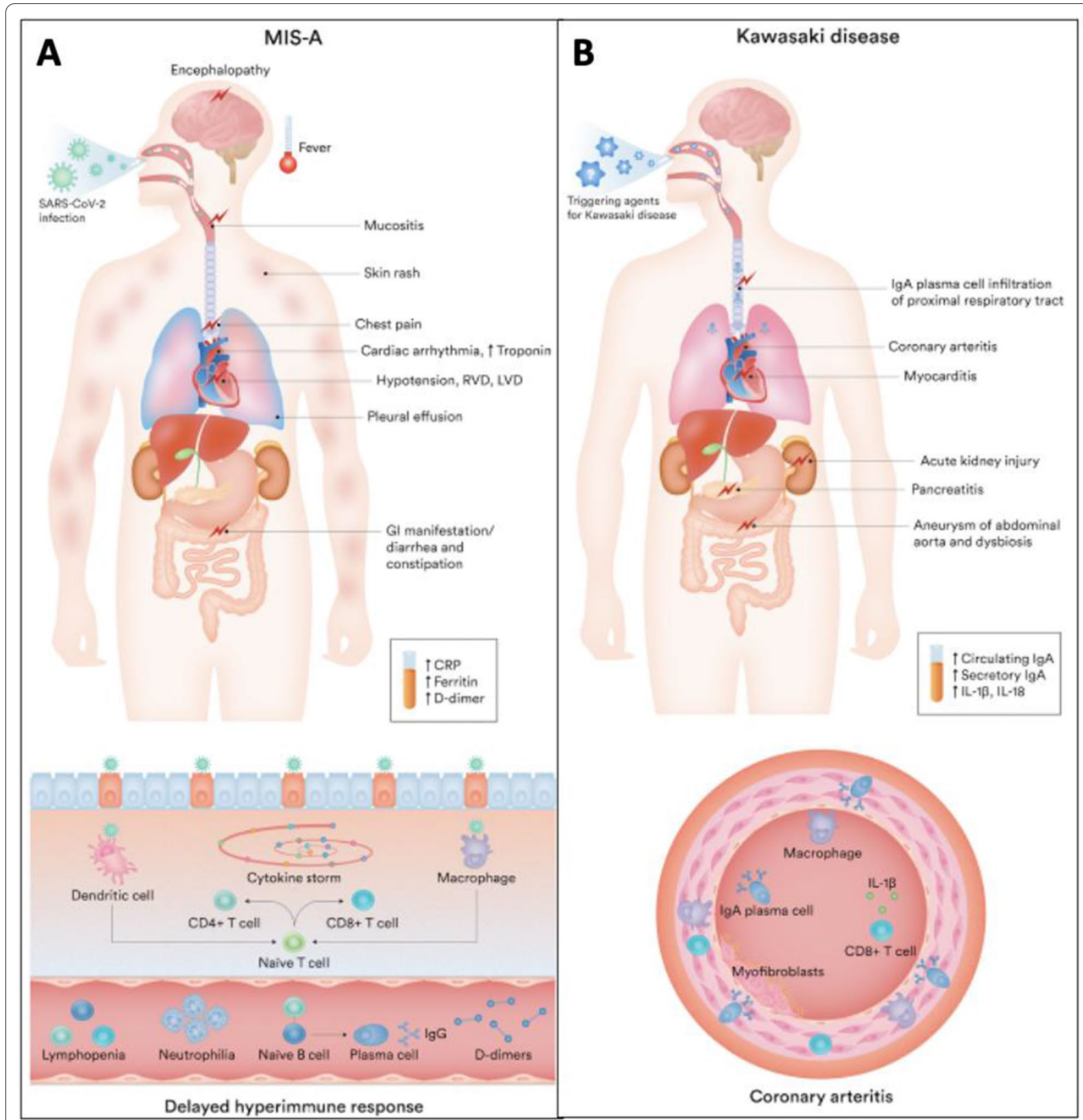

Fig. 1 Clinical manifestations and possible mechanism of injury in COVID MIS-A and Kawasaki disease. A MIS-A. B Kawasaki Disease. MIS-A multisystem inflammatory syndrome in adults, RVD right ventricular dysfunction, LVD left ventricular dysfunction, Gl gastrointestinal, CRP C-reactive protein, IgG immunoglobulin G, IgA immunoglobulin A, IL interleukin. This figure was created by Fardad Behzadi for the purposes of this publication

Cardiovascular impairment was also noted in the literature. Specifically, tachycardia $(22 / 36 ; 61 \%)$ and hypotension/cardiogenic shock with documented impaired ejection fraction $(23 / 36 ; 64 \%)[5-8,10,12,15,17-24]$. The left ventricular function/ejection fraction normalized with treatment in 15 patients $[6,7,12,17,21,23,24]$, of whom 7 patients received IVIG with or without aspirin [10, 12, 17, $23,24]$. Overall, $28 / 36$ (78\%) patients recovered and were safely discharged. Cardiac MRI has been discussed in the literature in terms of assessing for myocarditis. It can confirm signs of diffuse myocardial inflammation while ruling out ischemic or stress-induced cardiomyopathy [12]. 
There is no consensus on the mechanism causing MIS-A during or post-CoVID-19 infection. MIS-A is viewed as an atypical immune response causing systemic vasculitis and multiple acute organ injury. The dramatic response to IVIG and high-dose aspirin supports the occurrence of vasculitis, which was demonstrated in our patient. She was successfully weaned off vasopressors following the IVIG treatment, and discharged without any complications in her hospital course. Target management of MIS-A with immunomodulatory therapy has reversed acute kidney injury [25] and heart failure, with normalization of cardiac function in many patients $[6,7,12,17$, $21,23,24]$. Many theories were proposed to uncover the linkage between vasculitis and SARS-CoV-2 infection. For example, IL-6 increases markedly during CoVID-19 infection, and it is the same cytokine that mediates vasculitis in Kawasaki syndrome. IL-6 enhances the adhesion of lymphocytes to endothelial cells causing their damage [26]. Another theory points toward complement activation and capillary deposition of immune complexes as initial insult, which could be suggested in our case based on her low complement C3 and C4 levels [27].

MIS-A of CoVID-19 shares many similarities with Kawasaki-like multisystem inflammatory syndrome, a syndrome which has been linked to other viral infections. Diagnosis of Kawasaki disease requires (1) fever for ${ }^{>} 5$ days and (2) at least four signs of conjunctivitis, involvement of the oropharyngeal mucosa or IgA infiltration of the upper respiratory tract, cervical lymphadenopathy, rash, and extremity changes (edema or erythema) [28]. Furthermore, Kawasaki may present with acute kidney injury or aneurysms, especially in coronaries and abdominal aorta.

COVID-19 Kawasaki-like syndrome is diagnosed by (1) fever for ' 3 days, (2) at least two signs of rash, hypotension/shock, or acute cardiac injury (infarction, pericarditis, left ventricle dysfunction, right ventricular dysfunction, or coronary syndrome), (3) coagulopathy, or (4) acute gastrointestinal (GI) symptoms in the setting of elevated inflammatory markers (CRP, D-dimer, and/or ferritin) during or after COVID-19 infection, after excluding other infections [29]. This description was consistently seen with our patient. She exhibited fever, strawberry-like rash, hypotension requiring vasopressors, decreased ejection fraction, nephropathy, and significant elevations in her CRP and D-dimer.
Figure 1 illustrates the clinical features and possible pathophysiology basis of MIS-A and classic Kawasaki syndromes. Our patient did not fulfill the criteria of classic Kawasaki. Furthermore, the acute cardiac injury and hypotension, acute renal injury, fever, sore throat, unilateral lymphadenopathy, and elevated inflammatory markers in the setting of positive SARS-CoV-2 IgG antibody support a diagnosis of MIS-A.

In terms of management, there was considerable variation in treatment modalities when reviewing the literature. In our case, the patient was aggressively fluid resuscitated and started on broad spectrum antibiotics, steroids, and ultimately vasopressors. In conjunction with the infectious disease team, full-dose aspirin and IVIG was initiated, with resolution of her symptoms and ultimate discharge. To demonstrate the variability in treatments, we reviewed previously documented cases of MIS-A. Summarizing Table 2, 44\% of patients were given IVIG, $56 \%$ given steroids, $39 \%$ antibiotics, $13 \%$ given immunomodulators (tocilizumab, anakinra, cyclophosphamide, rituximab), $11 \%$ given aspirin, $22 \%$ anticoagulation, and 36\% requiring vasopressors. Despite the differences in management, recent literature studying the treatment modalities of MIS-C concluded that were was no evidence that IVIG alone or IVIG with steroids or immunomodulators leads to higher rates of recovery [30]. These findings may not be generalizable to the adult population who experience MIS-A, but it gives insight into the challenges of choosing a treatment modality.

\section{Conclusion}

Our case report is an example of the presentation, diagnosis, and management of MIS-A. As we dove into the literature and discovered other documented cases of MIS-A, we created Fig. 1 to illustrate the similarities and differences when compared with Kawasaki-like multisystem inflammatory syndrome. Our research into previous case reports illustrates the wide range of presentations, degree of end-organ damage, and treatment modalities. This diagnosis needs to be considered in the presence of recent COVID infection with new onset end organ failure, as prompt diagnosis and treatment is crucial for better outcomes. 


\section{Abbreviations}

MIS-A: Multisystem inflammatory syndrome in adults; ED: Emergency department; ICU: Intensive care unit; IVIG: Intravenous immunoglobulin; BMI: Body mass index; PCR: Polymerase chain reaction; CT: Computed tomography; POCUS: Point of care ultrasound; CRP: C-reactive protein; AST: Aspartate aminotransferase; ALT: Alanine aminotransferase; ALP: Alkaline phosphatase; BNP Brain natriuretic peptide; CDC: Centers for Disease Control; ESR: Erythrocyte sedimentation rate; IL-6: Interleukin-6.

\section{Acknowledgements}

Not applicable.

\section{Authors' contributions}

FB significant contribution to research, writing the manuscript, and creating tables/figures. NU significant contribution in research, writing and editing the manuscript. MD contribution in research, editing, and funding. All authors read and approved the final manuscript.

\section{Funding}

No funding was received for this study.

\section{Availability of data and materials}

Not applicable.

\section{Declarations}

\section{Ethics approval and consent to participate}

All procedures performed in studies involving human participants were in accordance with the ethical standards of the institutional and/or national research committee and with the 1964 Helsinki Declaration and its later amendments or comparable ethical standards.

\section{Consent for publication}

Written informed consent was obtained from the patient for publication of this care report and any accompanying images. A copy of the written consent is available for review by the Editor-in-Chief of this journal.

\section{Competing interests}

All the authors declare that they have no conflicts of interest

\section{Author details}

'Department of Internal Medicine, Aventura Hospital and Medical Center, Miami, FL, USA. ²Department of Emergency Medicine, Aventura Hospital and Medical Center, Miami, FL, USA. ${ }^{3}$ Department of Critical Care, Aventura Hospital and Medical Center, Miami, FL, USA.

Received: 11 January 2022 Accepted: 25 January 2022

Published online: 03 March 2022

\section{References}

1. Viner RM, Whittaker E. Kawasaki-like disease: emerging complication during the COVID-19 pandemic. Lancet (Lond, Engl). 2020:395(10239):1741-3.

2. Cheung EW, Zachariah P, Gorelik M, Boneparth A, Kernie SG, Orange JS, et al. Multisystem inflammatory syndrome related to COVID-19 in previously healthy children and adolescents in New York City. JAMA. 2020:324(3):294-6.

3. Morris SB, Schwartz NG, Patel P, Abbo L, Beauchamps L, Balan S, et al. Case series of multisystem inflammatory syndrome in adults associated with SARS-CoV-2 infection-United Kingdom and United States, MarchAugust 2020. MMWR Morb Mortal Wkly Rep. 2020;69(40):1450-6.

4. Kofman AD, Sizemore EK, Detelich JF, Albrecht B, Piantadosi AL. A young adult with COVID-19 and multisystem inflammatory syndrome in children (MIS-C)-like illness: a case report. BMC Infect Dis. 2020;20(1):1-4.
5. Lidder AK Pandit SA, Lazzaro DR An adult with COVID-19 kawasakilike syndrome and ocular manifestations. Am J Ophthalmol Case Rep. 2020:20:100875.

6. Tung-Chen Y, Algora-Martín A, Rodríguez-Roca S, Díaz de Santiago A. COVID-19 multisystemic inflammatory syndrome in adults: a not to be missed diagnosis. BMJ Case Rep. 2021;14(4):e241696.

7. Uwaydah AK, Hassan NMM, Abu Ghoush MS, Shahin KMM. Adult multisystem inflammatory syndrome in a patient who recovered from COVID-19 postvaccination. BMJ Case Rep. 2021;14(4):e242060.

8. Shaigany S, Gnirke M, Guttmann A, Chong H, Meehan S, Raabe V, et al. An adult with Kawasaki-like multisystem inflammatory syndrome associated with COVID-19. Lancet (Lond, Engl). 2020;396(10246):e8-10.

9. Fox SE, Lameira FS, Rinker EB, Vander Heide RS. Cardiac endotheliitis and multisystem inflammatory syndrome after COVID-19. Ann Intern Med. 2020;173(12):1025-7.

10. Li M, Haque W, Vuppala S, Tobias E. Rare presentation of multisystem inflammatory syndrome in an adult associated with SARS-CoV-2 infection: unilateral neck swelling. BMJ Case Rep. 2021;14(5):e242392.

11. Julius MA, Cantrell D, Sharif S, Zelnik Yovel D, Rapoport MJ. The first fatal post-COVID-19 adult patient with multi-system inflammatory syndrome in Israel. Israel Med Assoc J. 2021;23(4):212-3.

12. Hékimian G, Kerneis M, Zeitouni M, et al. Coronavirus disease 2019 acute myocarditis and multisystem inflammatory syndrome in adult intensive and cardiac care units. Chest. 2021;159(2):657-62. https://doi.org/10. 1016/j.chest.2020.08.2099.

13. Ahsan T, Rani B. A case of multisystem inflammatory syndrome postCOVID-19 infection in an adult. Cureus. 2020;12(12):e11961.

14. Bettach E, Zadok D, Weill Y, Brosh K, Hanhart J. Bilateral anterior uveitis as a part of a multisystem inflammatory syndrome secondary to COVID-19 infection. J Med Virol. 2021;93(1):139-40.

15. Razavi AC, Chang JL, Sutherland A, Niyogi A, Ménard GE. A 23-year-old man with multisystem inflammatory syndrome after mild COVID-19. J Investig Med High Impact Case Rep. 2020;8:2324709620974200.

16. Moghadam P, Blum L, Ahouach B, Radjou A, Lambert C, Scanvic A, et al. Multisystem inflammatory syndrome with particular cutaneous lesions related to COVID-19 in a young adult. Am J Med. 2021;134(1):e36-7.

17. Diakite S, Bousdira N, Tachon G, Ackermann F, Groh M, Rohmer J. Regression of coronary aneurysms with intravenous immunoglobulins and steroids for COVID-19 adult multisystem inflammatory syndrome. JACC Case Rep. 2021;3(4):581-5.

18. Gulersen M, Staszewski C, Grayver E, Tam Tam H, Gottesman E, Isseroff D, et al. Coronavirus Disease 2019 (COVID-19)-related multisystem inflammatory syndrome in a pregnant woman. Obstet Gynecol. 2021:137(3):418-22

19. Malangu B, Quintero JA, Capitle EM. Adult inflammatory multi-system syndrome mimicking Kawasaki disease in a patient with COVID-19. Cureus. 2020;12(11):e11750-e11750.

20. Othenin-Girard A, Regamey J, Lamoth F, Horisberger A, Glampedakis E, Epiney J-B, et al. Multisystem inflammatory syndrome with refractory cardiogenic shock due to acute myocarditis and mononeuritis multiplex after SARS-CoV-2 infection in an adult. Swiss Med Wkly. 2020;150(4546):20387.

21. Ahmad F, Ahmed A, Rajendraprasad SS, Loranger A, Gupta S, Velagapudi $M$, et al. Multisystem inflammatory syndrome in adults: a rare sequela of SARS-CoV-2 infection. Int J Infect Dis. 2021:108:209-11.

22. Mieczkowska K, Zhu TH, Hoffman L, Blasiak RC, Shulman KJ, Birnbaum M, et al. Two adult cases of multisystem inflammatory syndrome associated with SARS-CoV-2. JAAD Case Rep. 2021;10:113-5.

23. Veyseh M, Webster P, Blanco I. COVID-19-associated inflammatory syndrome in an adult woman with unexplained multiple organ failure: staying vigilant for COVID-19 complications as the pandemic surges. BMJ Case Rep. 2021;14(4):e242034

24. Bastug A, Aslaner H, Aybar Bilir Y, Kemirtlek N, Gursoy FM, Bastug $S$, et al. Multiple system inflammatory syndrome associated with SARS-CoV-2 infection in an adult and an adolescent. Rheumatol Int. 2021:41(5):993-1008 
25. Pérez A, Torregrosa I, D’Marco L, Juan I, Terradez L, Solís MÁ, et al. IgAdominant infection-associated glomerulonephritis following SARS-CoV-2 infection. Viruses. 2021;13(4):587.

26. Watson C, Whittaker S, Smith N, Vora AJ, Dumonde DC, Brown KA. IL-6 acts on endothelial cells to preferentially increase their adherence for lymphocytes. Clin Exp Immunol. 1996;105(1):112-9.

27. Licciardi F, Pruccoli G, Denina M, Parodi E, Taglietto M, Rosati S, et al. SARSCoV-2-induced Kawasaki-like hyperinflammatory syndrome: a novel COVID phenotype in children. Pediatrics. 2020;146(2):e20201711.

28. Stankovic K, Miailhes P, Bessis D, Ferry T, Broussolle C, Seve P. Kawasaki-like syndromes in HIV-infected adults. J Infect. 2007;55(6):488-94.

29. Jimenez-Cauhe J, Ortega-Quijano D, Carretero-Barrio I, Suarez-Valle A, Saceda-Corralo D, Moreno-Garcia del Real C, et al. Erythema multiformelike eruption in patients with COVID-19 infection: clinical and histological findings. Clin Exp Dermatol. 2020;45(7):892-5.

30. McArdle, et al. Therapy for multisystem inflammatory syndrome in children. N Engl J Med. 2021. https://doi.org/10.1056/NEJMc2111096.

31. Sokolovsky S, Soni P, Hoffman T, Kahn P, Scheers-Masters J. COVID-19 associated Kawasaki-like multisystem inflammatory disease in an adult. Am J Emerg Med. 2021;39:253-e1.

32. Parpas A, Yudd M, Dreisbach AW, Michaud J. Post COVID 19 multisystem inflammatory syndrome in an older adult. Ren Fail. 2021;43(1):530-2.

33. Balan S, Beauchamps L, Gonzales-Zamora JA, Vu C, Amoros A, Quiroz T, et al. Recovery does not always signal the end of the battle: a case of post SARS-CoV-2 multisystem inflammatory syndrome in an adult. IDCases. 2021;24:e01067.

\section{Publisher's Note}

Springer Nature remains neutral with regard to jurisdictional claims in published maps and institutional affiliations.

- fast, convenient online submission

- thorough peer review by experienced researchers in your field

- rapid publication on acceptance

- support for research data, including large and complex data types

- gold Open Access which fosters wider collaboration and increased citations

- maximum visibility for your research: over 100M website views per year

At BMC, research is always in progress.

Learn more biomedcentral.com/submissions 